\title{
Rural premedicine program aims to tackle doctor shortages
}

$\mathrm{J}$ ulie Schmidt began working at the medical clinic in remote Riondel, British Columbia at age 14 , but until recently, never dreamed she could become a doctor.

As a support staffer, she saw "everything from chainsaw emergencies to house calls," she says, but entrance to medical school seemed unattainable. "I was not able to take all the courses required at the high school I attended ... due to staffing, as well as how our classrooms were equipped."

Now, she's seeking admission to a new rural pre-medicine program at Selkirk College in nearby Castlegar, 41 $\mathrm{km}$ southwest of Nelson. A first in Canada, the three-year advanced diploma program aims to give rural students an alternate pathway to becoming competitive applicants for medical school, as well as a taste for rural medicine.

"This is an opportunity to provide the proper start to rural students who want to work in a rural setting," Neil Coburn, vice president of education and students at Selkirk, said in a press release. "If their primary pathway toward medical school starts in a small centre, the data show that when they graduate from medical school at an urban university, they are more likely to return to a rural setting."

Students enrolled in the program will complete requirements for entry to the University of British Columbia (UBC) Faculty of Medicine and Northern Medicine Program. They will also take courses to prepare for the medical college admission test and future rural practice, including courses in First Nations studies and small business management. All courses will include components tailored toward rural medicine.

"We can't compete with city colleges for size, but what we do have to offer is rural location and a lot of experience transitioning people from rural areas into university," says Elizabeth Lund, the program's coordinator.

Rural doctors and medical educators say the program has the potential to help address physician shortages in remote areas. Although roughly six million Canadians, representing 18\% of the population, live in rural regions, they are served by just 6400 or $14 \%$ of

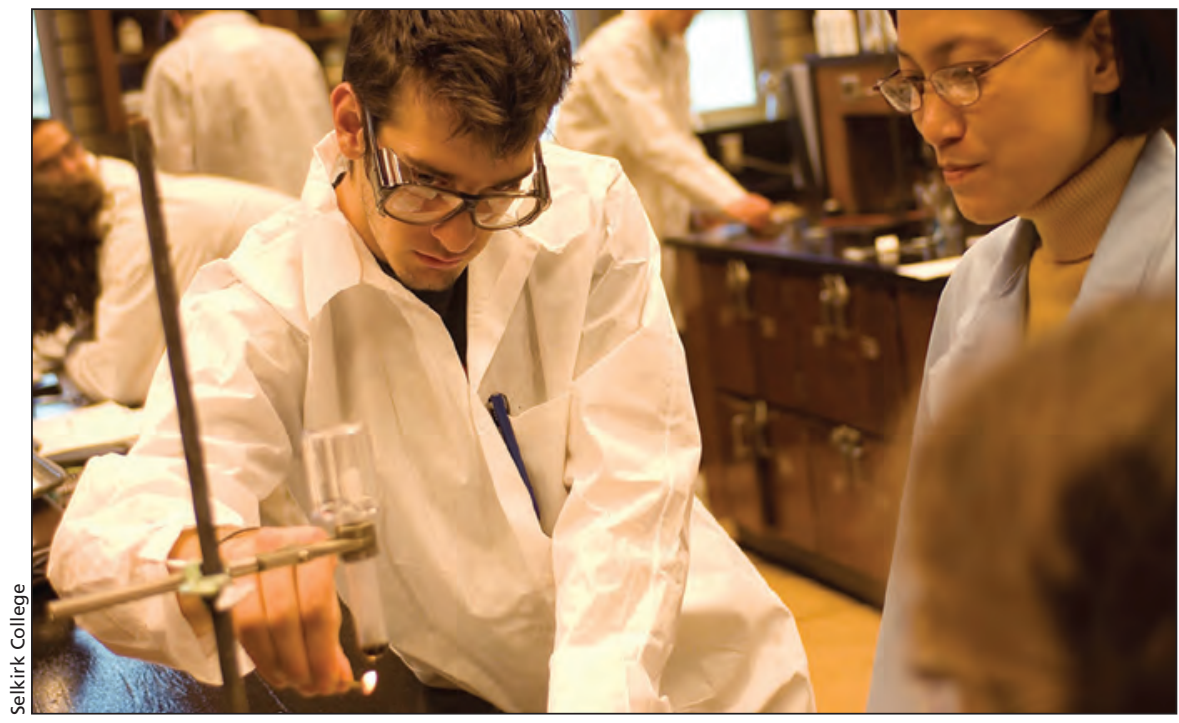

Students from remote areas are often less prepared in the sciences than their urban peers - a barrier that Selkirk's rural premedicine program hopes to breakdown.

family doctors, according to the Canadian Institute for Health Information.

"The early exposure to positive rural and remote experiences and mentors is essential to preparing students for rural practice as well as inspiring them to return to rural communities," says Dr. Jeanette Boyd, a family doctor in Nelson, BC. "The fact that they will be able to access this high standard of education closer to home, with the supports of their community and without incurring as great a financial debt as they would have by moving to a large urban centre will also remove some of the barriers that rural students face."

Rural students are underrepresented in medical schools across the country, in large part due to educational and economic disadvantage, according to the Society of Rural Physicians of Canada.

"Students from smaller communities are less well prepared in the sciences ... not because they don't have the capacity but because they don't have the quality of teaching," explains Dr. John Wootton, past president of the society.

Even those students with top marks may face financial challenges leaving their communities, "so they may write themselves out of the game from the get-go," Wootton says. "Programs which seek to encourage students from rural backgrounds to go into medicine are overall a promising way to change some of the demographics of the physician workforce, which is currently heavily slanted towards well-off, urban families."

In a letter of support for the program, Dr. Blair Stanley, a clinical assistant professor in the Department of Family Practice at UBC, called Selkirk's proposed curriculum "honestly spectacular" and forecast the rural pre-medicine program will "increase the number of rural students who get into medical school."

But according to Dr. Paul Winwood, vice provost medicine at the University of Northern British Columbia, a diploma from Selkirk's program "will not carry any particular weight in the admissions process."

Students who drop the program or decide to pursue other careers after graduating can transfer their credits towards a degree in another field. Selkirk is also developing an integrated rural health sciences diploma that would include additional streams preparing students for entry into fields such as pharmacy, dentistry, optometry, veterinary medicine and physiotherapy.

Selkirk College is accepting applications for the rural pre-medicine program until Feb. 28. The first cohort of 24 students will start courses in September 2014. — Lauren Vogel, CMAJ

CMAJ 2014. DOI:10.1503/cmaj.109-4700 